\title{
Study of Hardness and Crystallization Kinetics Due to Addition of Metals in $\mathrm{SSe}_{20}$ Chalcogenide Glasses
}

\author{
M.B. El-Den \\ Physics Department, Faculty of Science, Ain Shams University
}

The effect of adding $\mathrm{Ag}, \mathrm{Zn}$ and $\mathrm{Cd}$ on the glass forming ability, hardness and kinetics of crystallization of the binary system $\mathrm{SSe}_{20}$ has been studied. There is an increase in the value of the hardness due to the increase in the strength of chemical bonds formed by the added metals. Studies of the crystallization kinetics using the non-isothermal single scan technique show that no solid solution has occurred. Phase separation may occur during the preparation of the investigated compositions or during the heating process. 


\section{Introduction:}

There is a strong theoretical and experimental interest in the application of non-isothermal experimental analysis techniques to the study of phase transformation [1-5]. While isothermal experimental analysis techniques are in most cases more definitive, non-isothermal thermo-analytical techniques have several advantages. The simple rapid features with which non-isothermal experiments can be performed makes such types of experiments attractive. Non-isothermal experiments can be used to extend the temperature range of measurements rather than the isothermal experiments. Many phase transformations occur too rapidly to be measured under isothermal conditions because of transients inherently associated with the experimental apparatus. Industrial processes often depend on the kinetic behaviour of systems undergoing phase transformation under non-isothermal conditions. In this respect, a definitive measurements of non-isothermal transformation kinetic is desirable. The phase transformation of chalcogenide glasses in their binary and ternary systems have been widely studied by non-isothermal technique [3-6], because of their usage in numerous applications in semiconductor technology and their resent importance in optical recording system. The effect of metal addition on the physical properties of vitreous chalgocgenide semiconductors has been studied by many workers [7-10]. In the present paper the effect of addition of $20 \%$ atomic percentage of $\mathrm{Ag}, \mathrm{Zn}$ and $\mathrm{Cd}$ on the hardness, density and crystallization process of the compound $\mathrm{SSe}_{20}$ is studied.

\section{Experimental Technique:}

The investigated samples of the general formula $\left(\mathrm{SSe}_{20}\right)_{0.8} \mathrm{X}_{0.2}$ where $\mathrm{X}$ is different metals ( $\mathrm{Ag}, \mathrm{Zn}$ and $\mathrm{Cd}$ ) were prepared by heating and mixing the appropriate constituents of spectroscopic pure elements in evacuated $\left(10^{-2} \mathrm{~Pa}\right)$ silca tubes at $950^{\circ} \mathrm{C}$ for 3 hours and subsequently air quenched.

Thermal analysis experiments were carried out using Shimadzu instrument (DSC-50) with constant heating rate of $2{ }^{\circ} \mathrm{C} / \mathrm{min}$ in a nitrogen atmosphere flowing at $30 \mathrm{ml} / \mathrm{min}$ with $\alpha-\mathrm{Al}_{2} \mathrm{O}_{3}$ powder as a reference.

Hardness has been measured using Shimadzu microhardness tester. The load and loading periods were $50 \mathrm{gm}$ and $30 \mathrm{~s}$, respectively for all samples. For every sample the measurements were repeated at least 10 times, the deviation in the calculated values did not exceed $2 \%$. 


\section{Results and Discussion: \\ Thermal Induced Transformation}

The DSC thermograms for the studied compositions are shown in Fig. (1). They are characterized by the presence of the transition temperatures; the glass transition temperature $\left(T_{g}\right)$, the crystallization temperature $\left(T_{c}\right)$ and the melting temperature $\left(\mathrm{T}_{\mathrm{m}}\right)$. Table (1) summerizes the observed transition temperatures for all samples. The values of $\left(\mathrm{T}_{\mathrm{g}}\right)$ lie in the range $38.3-52{ }^{\circ} \mathrm{C}$. The value of $\left(\mathrm{T}_{\mathrm{c}}\right)$ for the parent composition $\operatorname{SSe}_{20}\left(78.3{ }^{\circ} \mathrm{C}\right)$ is decreased by the addition of 20 at.\% of different metals as given in Table (1). The value of $\left(\mathrm{T}_{\mathrm{m}}\right)$ lies in the range $208.2-212.3^{\circ} \mathrm{C}$ for all compositions.

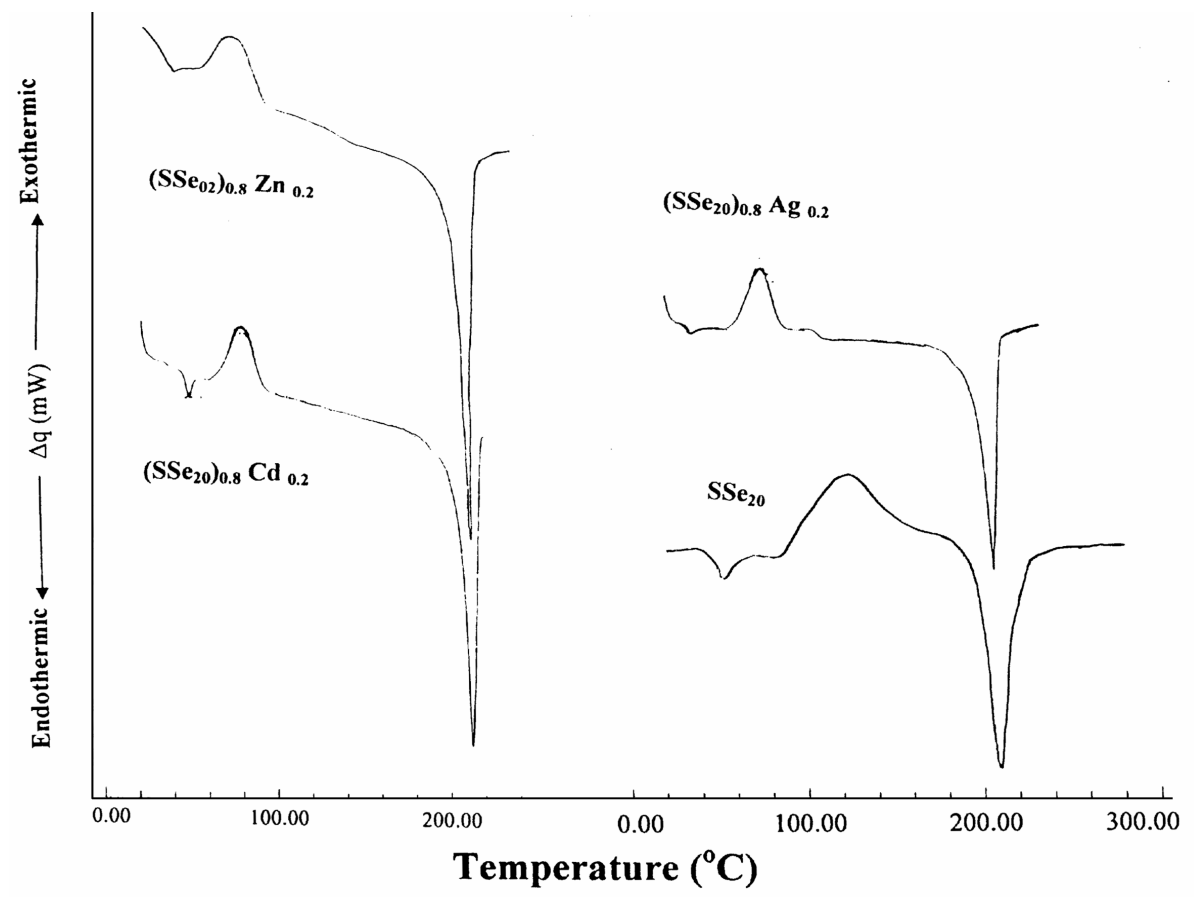

Fig. (1): DSC thermogram for the investigated compositions at heating rate $\phi=2{ }^{\circ} \mathrm{C} / \mathrm{min}$.

Table (1): Characteristic transition temperature, hardness and glass forming tendency of the investigated composition.

\begin{tabular}{|c|c|c|c|c|c|c|}
\hline Composition & $\begin{array}{c}\mathrm{T}_{\mathrm{g}} \\
\left({ }^{\circ} \mathrm{C}\right)\end{array}$ & $\begin{array}{c}\mathrm{T}_{\mathrm{c}} \\
\left({ }^{\circ} \mathrm{C}\right)\end{array}$ & $\begin{array}{c}\mathrm{T}_{\mathrm{m}} \\
\left({ }^{\circ} \mathrm{C}\right)\end{array}$ & $\mathrm{T}_{\mathrm{g}} / \mathrm{T}_{\mathrm{m}}$ & $\mathrm{K}_{\mathrm{gl}}$ & $\begin{array}{c}\mu \mathrm{H} \\
\left(\mathrm{Kg} / \mathrm{mm}^{2}\right)\end{array}$ \\
\hline $\mathrm{SSe}_{20}$ & 52.0 & 78.3 & 210.0 & 0.673 & 0.199 & 30.0 \\
$\left(\mathrm{SSe}_{20}\right)_{0.8} \mathrm{Ag}_{0.2}$ & 38.3 & 53.3 & 208.2 & 0.647 & 0.097 & 28.9 \\
$\left(\mathrm{SSe}_{20}\right)_{0.8} \mathrm{Zn}_{0.2}$ & 38.8 & 55.6 & 209.5 & 0.646 & 0.130 & 28.0 \\
$\left(\mathrm{SSe}_{20}\right)_{0.8} \mathrm{Cd}_{0.2}$ & 47.6 & 57.6 & 212.3 & 0.661 & 0.220 & 26.7 \\
\hline
\end{tabular}


A simple method of evaluating the glass forming tendency by DSC was proposed by Hurby [11]. The coefficient

$$
\mathrm{K}_{\mathrm{gl}}=\left(\mathrm{T}_{\mathrm{c}}-\mathrm{T}_{\mathrm{g}}\right) /\left(\mathrm{T}_{\mathrm{m}}-\mathrm{T}_{\mathrm{c}}\right)
$$

s a measure of the ease with which the glass can be formed. It has been calculated for the investigated glasses and given in Table (1). The values of $\mathrm{k}_{\mathrm{gl}}$ show the influence of metallic addition on the ability of $\mathrm{SSe}_{20}$ alloy to crystallize. Also, Table (1) shows the compositional dependence of the reduced glass transition $T_{g} / T_{m}$ which has been thought to be one of the dominant factors for glass formation [12]. It was found that the empirical rule between $T_{m}$ and $T_{g}$ of Kauzman [13].

$$
\mathrm{T}_{\mathrm{g}} / \mathrm{T}_{\mathrm{m}}=2 / 3
$$

is established easily and holds very well, since the experimental values lie between 0.661 and 0.673 for the investigated composition. This means that though glass formation for these samples may be easy. Thus, the addition of $\mathrm{Ag}, \mathrm{Zn}$ and $\mathrm{Cd}$ to $\mathrm{SSe}_{20}$, which shifts the value of $\mathrm{K}_{\mathrm{gl}}$ and the characteristics temperature $T_{g}, T_{c}$ to lower values,may lead to less stable glasses at temerature near to room temperature.

The stability of these compositions has been studied by carrying out the DSC thermograms of the composition $\left(\mathrm{SSe}_{20}\right)_{0.8} \mathrm{Ag}_{0.20}$ at two different heating rates $\phi=5$ and $15^{\circ} \mathrm{C} / \mathrm{min}$ as shown in Fig. (2). The DSC trace shows that, two glass transition temperatures, $\mathrm{T}_{\mathrm{g}}=$ $38.20{ }^{0} \mathrm{C}$ and $47.50{ }^{0} \mathrm{C}$ at $\Phi=5^{0} \mathrm{C}$ which seems to indicate that phase separation had taken place during the preparation of the bulk glass. Also, in the

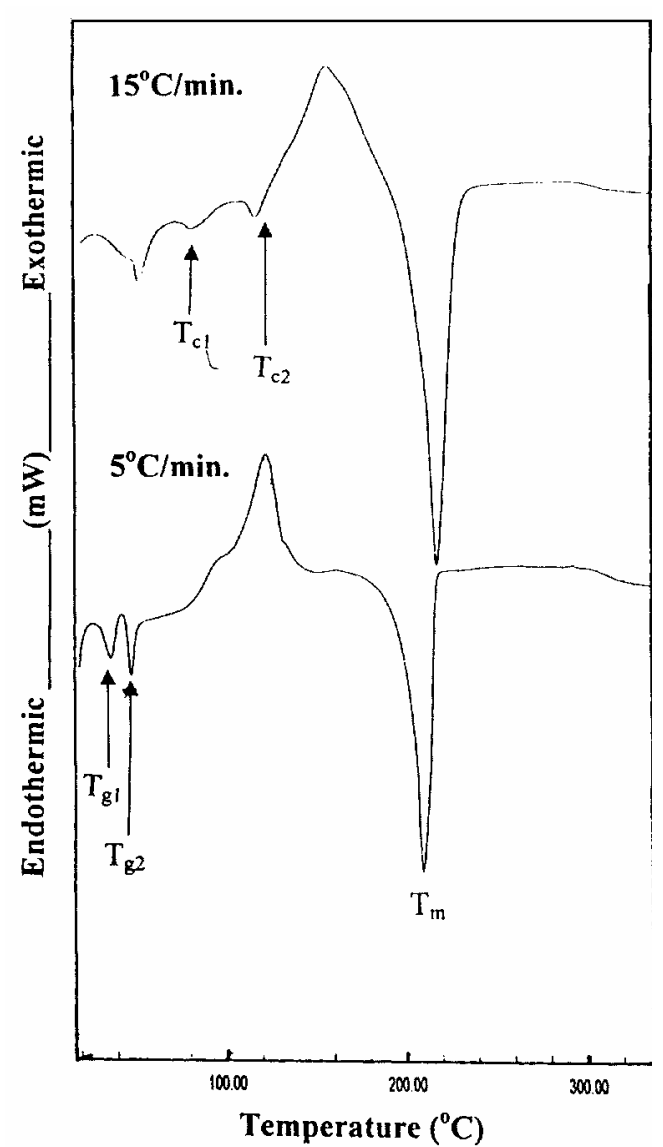

Fig. (2): DSC thermogram for the $\left(\mathrm{SSe}_{20}\right)_{0.8} \mathrm{Ag}_{0.2}$ at heating rates $\phi=5,15^{\circ} \mathrm{C} / \mathrm{min}$. 
thermogram there are two exothermic peaks, at $\mathrm{T}_{\mathrm{c}}=86.79{ }^{\circ} \mathrm{C} \& 118.40{ }^{\circ} \mathrm{C}$ and one endothermic peak, which means that the two crystalline phases have similar melting points. Kinser et al. [14] and Bagley [15] have shown that theye thermodynamic tenden for phase separation increases as the number of components increases.

The change of the sample hardness $\mathrm{VH}$ associated with the introduction of metallic elements $\mathrm{Ag}, \mathrm{Zn}$, and $\mathrm{Cd}$ to $\mathrm{SSe}_{20}$ is given in Table (1). It shows that the effect of adding different metals to $\mathrm{SSe}_{20}$ glassy compound might be correlated with the concentration and strength of chemical bonds formed in the network structure of the materials investigated. There are two types of chemical bonds in $\mathrm{SSe}_{20}$, the S-Se and the Se-Se bonds which are of ratio 1:10. They are of strength 88 and $79 \mathrm{Kcal} / \mathrm{mole}$, respectively. The addition of $20 \%$ of $\mathrm{Ag}, \mathrm{Zn}$ and $\mathrm{Cd}$ to $\mathrm{SSe}_{20}$, would replace the Se atoms in Se-Se bond . So, Se-Ag, Se-Zn and Se-Cd bonds of lower strength: 48.4, 40.8 and $30.5 \mathrm{Kcal} / \mathrm{mol}$, respectively,will form leading to the hardness decrease as shown in Table (1).

\section{Kinetics of the crystallization}

Kinetics of the crystallization process have been investigated using simple scan technique through an improved DSC model[16,17]. Previous studies on selenium like structure system ,as Se-Te [18] and Se-S [19] and metallic glasses [20,7] have shown the utility of this technique for studying thermally activated crystallization kinetics in the chalcogenide glasses.

The fraction $\alpha$ transformed after a given time $t$ (or temperature $\mathrm{T}$ ) can be calculated from the thermogram using the Borchardt assumption [19] and the partial area analysis [22-24],

$$
\alpha=\mathrm{a}(\mathrm{T}) / \mathrm{A}
$$

where A is the total area of the exothermic peak and a (T) is the area of the exothermic peak at temperature $\mathrm{T}$.

An estimation of the complex activation energy of crystallization $E_{c}$ can be made by using Piloyan's method [25]. This is based on the differential form of the model relation for $\alpha$, known as $\mathrm{g}(\alpha)$, and on Borchard's assumption [21], that the reaction rate, $d \alpha / d t$, is proportional to innert reference, $\Delta q$, as detected by DSC. This means that the kinetic eqution,

$$
-\ln (1-\alpha)=\mathrm{K}_{\mathrm{o}} \mathrm{t}^{\mathrm{n}} \exp \left(-\mathrm{E}_{\mathrm{c}} / \mathrm{RT}\right)
$$

which was formally derived by Avrami [26], has been differentiated to yield

$$
\mathrm{d} \alpha / \mathrm{dt}=\mathrm{n} \mathrm{K}_{\mathrm{o}}{ }^{1 / \mathrm{n}}\left\{\exp \left(-\mathrm{E}_{\mathrm{c}} / \mathrm{RT}\right)^{1 / \mathrm{n}}\right\} \mathrm{f}(\alpha)
$$


where

$$
f(\alpha)=(1-\alpha)\{-\ln (1-\alpha)\}^{(\mathrm{n}-1) / \mathrm{n}}
$$

Here, $\mathrm{K}_{\mathrm{o}}$ is considered to be constant with respect to temperature. For a constant heating rate $\phi=\mathrm{dT} / \mathrm{dt}$, Equ. (5) is separable in $\alpha$ and $\mathrm{T}$ and can therefore be directly Integrated. The Integration yields ;

$$
\left\{\ln (1-\alpha)^{-1}\right\}^{\frac{1}{n}}=\frac{E_{c} K_{o}^{1 / n}}{\phi R} P(x)=g(\alpha)
$$

where $\mathrm{x}=\mathrm{E} / \mathrm{nRT}$. Different types of approximations are used and has been reviewed in ref. [27]. For a limited range, i.e. a normal temperature interval of about $100{ }^{\circ} \mathrm{C}, \mathrm{P}(\mathrm{x})=\exp (\mathrm{x})$. Therefore, Equ. (7) can be written in logarithmic form as :

and

$$
\ln \{-\ln (1-\alpha)\}=\mathrm{n}\left[\ln \left(\mathrm{K}_{\mathrm{o}}{ }^{1 / \mathrm{n}} \mathrm{E}_{\mathrm{c}}\right) / \phi \mathrm{R}\right]-\mathrm{E}_{\mathrm{c}} / \mathrm{RT}
$$

$$
\ln \{\mathrm{g}(\alpha)\}=\left[\ln \left(\mathrm{K}_{\mathrm{o}}{ }^{1 / \mathrm{n}} \mathrm{E}_{\mathrm{c}} / \mathrm{R}_{\mathrm{T}}\right]-\mathrm{E}_{\mathrm{c}} / \mathrm{nRT}\right.
$$

A typical plots of $\ln \{-\ln (1-\alpha)\}$ versus $1 / \mathrm{T}$ gives $\mathrm{E}_{\mathrm{c}}$ as shown in Fig. (3) for the investigated compositions. The plot, found to be linear over most of the temperature range but in the region of large crystallized fraction $\alpha>0.7$, a change in the linearity is seen. This change in slope is attributed to a phase separation, which might have occurred during the preparation of the sample, or during heating of the sample. This phase separation can be described by different values of the activation energy of crystallization $E_{c}$. Table (2) gives the values of $\mathrm{E}_{\mathrm{c}}$ for different phases of all examined composition. 


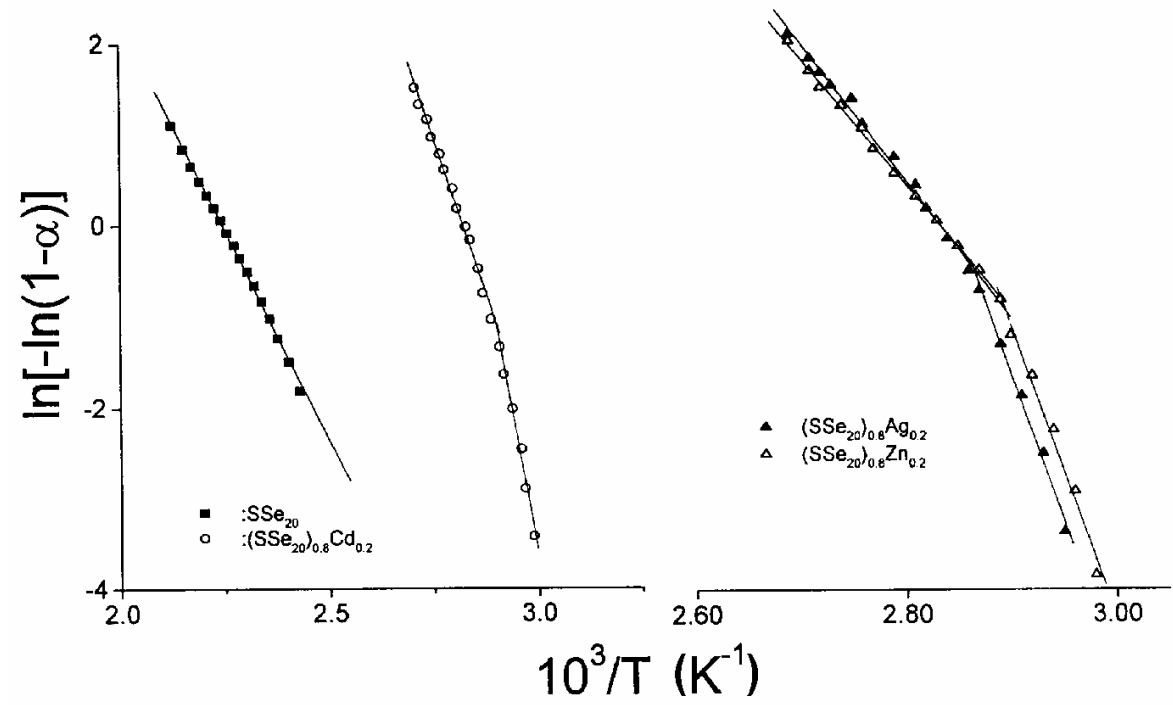

Fig. (3): Plots of $\ell \mathrm{n}[-\ell \mathrm{n}(1-\alpha)]$ versus $1 / \mathrm{T}$ for the investigated compositions

Table (2): The activation energy and the order of crystallization of the investigation composition.

\begin{tabular}{|l|c|c|c|c|}
\hline \multirow{2}{*}{ Composition } & \multicolumn{2}{|c|}{$\begin{array}{c}\text { Activation energy, } \\
\text { (Kcal/mol) }\end{array}$} & \multicolumn{2}{c|}{ Crystallization order, $\mathbf{n}$} \\
\cline { 2 - 5 } & $\mathbf{1}^{\text {st }}$ phase & $\mathbf{2}^{\text {nd }}$ phase & $\mathbf{1}^{\text {st }}$ phase & $\mathbf{2}^{\text {nd }}$ phase \\
\hline $\mathrm{SSe}_{20}$ & 19.9 & ----- & 1 & ------ \\
$\left(\mathrm{SSe}_{20}\right)_{0.8} \mathrm{Ag}_{0.2}$ & 28.97 & 63.9 & 1.94 & 1.96 \\
$\left(\mathrm{SSe}_{20}\right)_{0.8} \mathrm{Zn}_{0.2}$ & 25.97 & 60.3 & 2.0 & 1.98 \\
$\left(\mathrm{SSe}_{20}\right)_{0.8} \mathrm{Cd}_{0.2}$ & 27.37 & 50.81 & 1.98 & 1.95 \\
\hline
\end{tabular}

Comparing the experimental data with different kinetic equations [28, 29] showed that for random nucleation, the function $\{-\ln (1-\alpha)\}^{1 / 2}=\mathrm{KT}$ closely approximates a linear behaviour over the whole range of a $(0<\alpha<1)$, with respect to the first and second peak of crystallization. A plot of $\ln g(\alpha)$ versus $1 / \mathrm{T}$ yields a straight line as shown in Fig. (4), its slope equals $E_{d} / n R$. The Avrami exponent $\mathrm{n}$, which reflects the nucleation rate and/or the growth morphology, were determined and given in Table (2). The values of $\mathrm{n}$ lie in the range of 1.0-2.0 for all stages of crystallization of the examined compositions, which means that the transformation proceeds throught two dimensional growth. The nearly constant value of $n$ (1.94- 2.0) for the compositions of $\left(\mathrm{SSe}_{20}\right)_{0.8} \mathrm{Ag}_{0.2},\left(\mathrm{SSe}_{20}\right)_{0.8} \mathrm{Cd}_{0.2}$, and $\left(\mathrm{SSe}_{20}\right)_{0.8} \mathrm{Zn}_{0.2}$ indicates that the rate of increase of the nuclei is constant during their crystallization. 


\section{T. In}

Fig. (4): Plots of $\log [g(\alpha)]$ versus $1 / \mathrm{T}$ for the investigated compositions.

\section{Conclusions:}

It can be concluded that :

1- The addition of 20 at $\%$ of $\mathrm{Ag}, \mathrm{Zn}$ and $\mathrm{Cd}$ metal to the glassy compound $\mathrm{SSe}_{20}$ decreases: a) the glass transition temperature $\left(\mathrm{T}_{\mathrm{g}}\right)$ of the investigated compositions which means that less stable glasses is obtained, b) the hardness which is due to the change in the strength of chemical bonds formed in the network structure.

2- There are two values of the activation energy of crystallization Ec of the investigated samples which mean that, a phase separation might have occurred during the preparation of the sample or during heating of the sample.

3- The values of the order of crystallization, $n$, for all stages of crystallization of the examined compositions lie in the range 1.0-2.0 which means that the transformation proceeds through two dimensional growth.

4- Phase separation phenomena is important for the preparation and application of amorphous chalcogenides, because it strongly influence the ability to quench and maintain homogeneous amorphous solution.

\section{References:}

1. M.H. El-Fouly, and J.T. Edmond, phys. stat. solidi (a), 21, 43 (1974).

2. D.D. Thornburg, R.I. Johnson, and T.M. Hayes, Proc. $5^{\text {th }}$ Conf. On Amorphous and Liquid S.C. at Garmish, Partenkirchen, (1973). 
3. M.F. Kotkata, M.H. El-Fouly and M.B. El-Den, Latin American J. Metallurgy \& Materials, 5, 28 (1985).

4. N. Afify, J. Non-cryst. Solids, 142, 247 (1992).

5. L.A.Wahab, M.B.El-Den and M.S.Youssef, Egypt. J.Solids, 23, 71 (2000).

6. D.D. Thornburg and R.I. Johnson, J. Non-Cryst. Solids, 17, 2 (1975).

7. L.A. Wahab, K. Sedeek, A. Adam, Materials Chemistry and Physics, 59, 232 (1999).

8. P. Clechet, C. Marlelet and N. Gunney Dinhcau, J. Thermal Analysis 16, 59 (1979).

9. J.T. Edmond, J. Non Cryst. Solids 1, 39 (1968).

10. A.A. Andreen, Z.U. Borisova and E.A. Bichkov. Yu. G. Vlasov, J. Noncryst. Solids , 35, 901 (1980).

11. A. Hrubey Czech, J. Phys. Ser. B.22, 1187 (1972).

12. H.A. Davies, "Amorphous Metallic Alloys", ed. F.E. Lubrosky, Butterworth London, p. 8 (1983).

13. W. Kauzmann, Chem. Rev., 43, 219 (1948).

14. D.L. Kinser, L.K. Wilson, H.R. Sanders, and D.J. Hill, J. Non- Cryst. Solids, 8-10, 598 (1972).

15. B.G. Bagley, Electronic Properties o Amorphous S.C. Edited by J. Tauc (New York, Plenum Press), (1974).

16. J.Sestak, Phys. \& Chem. Of Glasses, 15, 134 6(1974).

17. T. Kemny, Thermochemica Acta, 110, 131 (1987).

18. M.F. Kotkata and E.A. Mahmoud, Mat. Sci. Eng. 54, 163 (1982).

10. M.F. Kotkata, M.H. El Fouly, A.Z. El Behay and L.A. Wahab, Mat. Sci. Eng. 60, 163 (1983).

20. E.A. Mahmoud, L.A. Wahab, M.A. Mahmoud and G.A. Abdel- Ghaffar, Al-Azhar Bull. Sci., 9, 593 (1998).

21. H.J. Borchardt, J. Inorg. Nucl. Chem., 12, 252 (1960).

22. N. Afify, J. Non Cryst. Solids, 128, 279 (1991).

23. N. Rysava, T. Spasov and L.Tichy, J. Thermal Analysis, 32, 10115 (1987).

24. S. Mahadevan, A. Giridhar and A.K. Singh, J. Non. Cryst. Solids, 88, 11 (1986).

25. F.O. Piloyan, I.O. Ryabchikov and O.S. Novikova, Nature 212, 177 (1941).

26. M. Avrami, J. Chem. Phys. 7, 1103 (1939); 8, 212 (1940); 9, 177 (1941).

27. J. Sestak, Thermochim. Acta, 3, 150 (1971).

28. V. Satava and F.G. Skavara, J. Amer. Ceram. Soc. 52, 591 (1969).

29. J.H. Sharp, G.V. Brindly and B.N. Achar, J. Amer. Ceram. Soc., 49, 369 (1966). 